\title{
Survey of Relationship between Strategic Thinking within Deployment of Knowledge Managment and Organizational Innovation in Miandoab NIOPDC
}

\author{
Morteza Shahbazzadeh ${ }^{1}$ \\ Azam Rahiminik ${ }^{2}$ \\ Abbas Saleh Ardestani ${ }^{3}$

\begin{abstract}
${ }^{1}$ Department of Executive Management, Electronic Branch, İlamic Azad University, Tehran, Iran ${ }^{2}$ Assistant professor of Business Management, Islamic Azad University Central Tehran Branch, Tehran, Iran Corresponding Author Email: Arnik2004@yahoo.com
\end{abstract} \\ ${ }^{3}$ Departments of Management, Islamic Azad University Central Tehran Branch, Tehran, Iran
}

Doi:10.5901/mjss.2016.v7n4s1p294

\begin{abstract}
Strategic thinking is like a lever that paves the way for organization to achieve improved performance. But it should be noted that strategic thinking mostly emphasizes on activities that must not be performed. The purpose of the present study is to explore the relationship between strategic thinking and the establishment of knowledge management as well as organizational innovation. The sample consisted of all employees (180) of the National Oil Products Distribution Company in Miandoab region. According to Cochran formula, the sample is set equal to 120. The nature of this study is non-experimental, and its purpose is applied. To collect data, survey method was used. The type of the study is descriptive-analytical. The questionnaire, used as a measurement tool, had a good reliability and validity. To analyze the data, SPSS 18 and Lisrel 18.5 softwares were used and Kolmogorov-Smirnov test, Pearson correlation coefficient, and exploratory factor analysis were examined. The results of the study confirmed the researcher's hypothesis that there is a relationship between strategic thinking and the establishment of knowledge management and organizational innovation at the National Oil Products Distribution Company in Miandoab region.
\end{abstract}

Keywords: strategic thinking, organizational achievement, and improved performance

\section{Introduction}

Nowadays, the managers of various organizations are aware of the importance of knowledge management function and its role in the organization and each organization is trying to acquire this new knowledge. Therefore, the use of strategic thinking for knowledge management can improve organizational goals. Another important factor that provides the necessary conditions for growth and innovation development is the creation of "strategic thinking" in the organization ( 1 \& 2). Strategic thinking in both individual and organizational levels can provide integrity and certain foresight. On one hand, this can help staffs have a better understanding of the organization and its operating environment that results in their frequent creativity. On the other hand, this can provide communication and interaction between managers and employees that leads to the exploitation of the ingenuity and creativity of employees in the organization (3). According to "Heracles", strategic thinking is like double-loop learning: one challenges existing assumptions and the other develops new and innovative solutions which finally results in the more appropriate potential actions in an organization (4 \& 5). Thus, if an organization can achieve a position that most managers and employees can think strategically and also consider the innovation issue strategically, they will always question the status quo in order to achieve newer and better solutions. In addition, they support and guide those who join their organization. In this way, people have a favorable perspective regarding the organization and themselves in future, and, within this framework, they will achieve a better understanding of the organization and its operating environment. Finally, creativity and innovation will be developed in order to achieve this favorable perspective and adapt the organization to the environment (6).

When the environmental conditions change, strategic thinking increases the appropriate and timely response capability. Strategic thinking is a collection of shared mental images of a society and reflects the beliefs, attitudes, knowledge, and values of society. To the extent that these mental images and roles are more complete and higher in an organization and fit the organization's goals and strategies, the smoother the path of success for the organization will be. Different perceptions, thoughts, and mental images of individuals in dealing with issues have a significant impact on 
strategic thought and culture $(7 \& 8)$.

Cultural and structural factors such as complexity, formalization, centralization, and organizational culture are the other factors that affect appropriate infrastructure to create and foster innovation. If the organization is complicated at the horizontal level (the number of jobs and tasks) or at the vertical level (the number of managerial positions) and its organizational relationships become more legal and formal, the possibility of group interaction is strongly reduced and this keeps the organization away from its innovative goals. Besides, if the organization has a high level of formalization, individuals do not have freedom of action, and tasks have not an acceptable and tolerable flexibility, the staffs will not have a creative and innovative behavior. In contrast, if the organization accepts learning, flexibility, and risktaking as the core principles, and also staffs can make proper decisions and judgements based on their own intellectual and administrative power and can design and produce appropriate reaction without concentration at the right time, the context for the use of individual creativity will be prepared $(9,10, \& 11)$. It is worth mentioning that there have been plenty of studies on various subjects such as medical science, engineering, humanities, etc. in this geographical region, but there is a paucity of research on this important area $(12,13,14,15,16,17,18,19,20$, \& 21).

Therefore, the present study aims to explore the relationship between strategic thinking and knowledge management as well as organizational innovation at the National Oil Products Distribution Company in Miandoab region. Therefore, the question of this study is: what is the relationship between strategic thinking and knowledge management as well as organizational innovation at the National Oil Products Distribution Company in Miandoab region?

\section{The conceptual framework and theoretical model}

In today's dynamic and competitive environment, the importance of applying strategic thinking against competitors is obvious to every knowledgable manager. In today's dynamic and competitive market, the importance of adherence to appropriate competetive strategy thinking that suits against competitors leads to stabilizing the organization's position and creation of knowledge management and organizational innovation. Knowledge includes formal knowledge, patterns, rules, programs, procedures, skills, and experience of individuals. Besides, knowledge management includes official knowledge, interact, analyzing the situations, developing new solutions to problems, doing tasks of the organization, cultural issues, customs, and values such as contacting with the audience of the organization. Although knowledge management has been considered as a management tool to increase effeciency, efficiency and innovation are generally accepted as principles of knowledge management under development. At the same time, the position of the organization in relation to other players in the industry determine its profit, and the organization which is able to place itself in a suitable position compared to its competitors will gain higher profit than the average of that industry. Moreover, despite the existence of improper industrial structure, such an organization will prosper and return its investment rapidly.

Therefore, as said before, according to the concern of the National Oil Products Distribution Company of Miandoab, in order to assess the relationship between knowledge management and organizational innovation as well as other issues relating to this subject, this study used the following model. In fact, the conceptual model of this study is adapted from the model used in the reseach of Moon et al. (2013). This model connects internal and external variables to strategic thinking, which in turn are related to knowledge management and organizational innovation. Strategic thinking includes: long-term attitudes and attitude toward risk taking, reward system and top managers, formalization, centralization and internal teams, and the organization's resources and capabilities which are determined as deterrent domestic and encouraging strategic thinking variables at the organizational level. In addition, market volatility and instability of technology are considered as other strategic thinking variables. Finally, the relationship between strategic thinking and knowledge management as well as organizational innovation at the National Oil Products Distribution Company in Miandoab region is investigated.

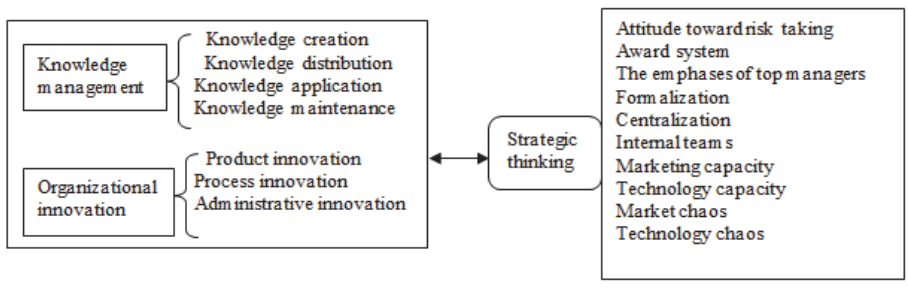

Figure A: The conceptual model of the study (Moon et al., 2013) 


\section{Methodology}

This study is non-experimental in nature and its purpose is applied. For data collection, survey method was used. The type of the study is descriptive-analytical. When the purpose is to solve the problems of the organization using the results, the research is called applied. Survey is a method to obtain information about the attitudes, beliefs, opinions, motivations or the characteristics of a group of a community. Descriptive research deals with how things are done, and explanatory research deals with why things happen.

The sample of this study was all the staffs of the National Oil Products Distribution Company in Miandoab which is located in West Azerbaijan province in Iran. They were approximately 180 individuals. Therefore, using Cochran formula and Morgan table, 120 individuals were selected as sample.

In this study, in order to collect data and the necessary information to answer the research questions, documentary method (going to the library to gather resources and necessary information to review the theoretical and empirical literature) and field method (the completed questionnaire by the participants) were used. The material of the study was a questionnaire developed by the researcher based on the conceptual model.

In the present study, the Cronbach's alpha was used to calculate the reliability of the questionnaire. The following table shows the results:

Table 1: Cronbach's alpha coefficients for the strategic thinking questionnaire

\begin{tabular}{|l|c|}
\hline Variables & Cronbach's alpha coefficient \\
\hline Top managers' attitude towards risk-taking & $77 \%$ \\
\hline Award systems & $78 \%$ \\
\hline The emphases of top managers & $79 \%$ \\
\hline Formalization in organizational structure & $77 \%$ \\
\hline Centralization in organizational structure & $75 \%$ \\
\hline Internal teams & $77 \%$ \\
\hline Marketing capacity & $76 \%$ \\
\hline Technology capacity & $78 \%$ \\
\hline Market chaos & $76 \%$ \\
\hline Technology chaos & $77 \%$ \\
\hline
\end{tabular}

Table 2: Cronbach's alpha coefficients for the knowledge management questionnaire

\begin{tabular}{|l|c|}
\hline Knowledge management variables & Cronbach's alpha coefficients \\
\hline Knowledge creation & $81 \%$ \\
\hline Knowledge distribution & $82 \%$ \\
\hline Knowledge application & $79 \%$ \\
\hline Knowledge maintenance & $78 \%$ \\
\hline
\end{tabular}

Table 3: Cronbach's alpha coefficients for the organizational innovation questionnaire

\begin{tabular}{|l|c|}
\hline The aspects of the organizational innovation & Cronbach's alpha coefficients \\
\hline Product innovation & $79 \%$ \\
\hline Process innovation & $81 \%$ \\
\hline Administrative innovation & $81 \%$ \\
\hline
\end{tabular}

In order to analyze the data and applying statistical analysis, SPSS and Lisrel softwares were used. Exploratory factor analysis was used to assess the validity of variables.

\section{Results}

\subsection{The distribution of the participants according to gender}

Table 1: Frequency of the participants' distribution according to gender

\begin{tabular}{|l|c|}
\hline Gender & Frequency \\
\hline Male & 20 \\
\hline Female & 100 \\
\hline Total & 120 \\
\hline
\end{tabular}


The above table shows that 100 participants (83/3\%) were male and 20 participants (23/7\%) were female.

\subsection{Distribution of the participants according to age}

Table 2: Distribution of the participants according to age

\begin{tabular}{|l|c|}
\hline Age (year) & Frequency \\
\hline $25-30$ years & 20 \\
\hline $31-36$ years & 20 \\
\hline $37-42$ years & 30 \\
\hline $43-48$ years & 30 \\
\hline 49 years and older & 20 \\
\hline Total & 120 \\
\hline
\end{tabular}

According to the above table, 20 participants (16/7\%) were in the $25-30$ age range, 20 participants (16/7\%) were in the $31-36$ age range, 30 participants (25\%) were in the $37-42$ age range, 30 participants (25\%) were in the $43-48$ age range, and 20 participants (16/7\%) were 49 years and older.

\subsection{Distribution of the participants according to education}

Table 3: Distribution of the participants according to education

\begin{tabular}{|c|c|}
\hline Education & Frequency \\
\hline BA & 45 \\
\hline MA & 70 \\
\hline PhD & 5 \\
\hline Total & 120 \\
\hline
\end{tabular}

As the above table indicates, in this study 45 participants (37/5\%) had BA, 70 participants (58/4\%) had MA, and 5 participants (4/16\%) had PhD.

\subsection{Distribution of the participants according to work experience}

Table 4: Distribution of the participants according to work experience

\begin{tabular}{|l|c|}
\hline Work experience & Frequency \\
\hline $5-10$ years & 25 \\
\hline $11-16$ years & 45 \\
\hline $17-22$ years & 35 \\
\hline 23 years and above & 15 \\
\hline Total & 120 \\
\hline
\end{tabular}

Accrding to table 4, 25 participants (20/9\%) had 5-10 years work experience, 45 participants (37/5\%) had 11-16 years work experience, 35 participants (29/1\%) had 17-22 years work experience, and 15 participants had 23 years (12/5\%) and more work experience.

\section{Analysis and description of research variables}

The descriptive findings of the research, statistical indices such as mean, standard deviation, and dispersion coefficient of all variables are presented in Table 5.

Table 5: Descriptive indices of the research model variables

\begin{tabular}{|l|c|c|c|}
\hline Statistical indices of variables & Average & Standard deviation & dispersion coefficient \\
\hline Attitude toward risk & $5 / 53$ & $1 / 12$ & $20 / 25$ \\
\hline Award system & $5 / 33$ & $0 / 84$ & $15 / 76$ \\
\hline Emphases of top managers & $5 / 33$ & $1 / 02$ & $19 / 14$ \\
\hline Formalization & $5 / 60$ & $0 / 87$ & $15 / 53$ \\
\hline
\end{tabular}




\begin{tabular}{|l|l|l|l|}
\hline Centralization & $4 / 56$ & $1 / 27$ & $27 / 85$ \\
\hline Internal teams & $5 / 57$ & $0 / 83$ & $14 / 90$ \\
\hline Market capacity & $5 / 28$ & $0 / 95$ & $17 / 99$ \\
\hline Technology capacity & $5 / 10$ & $0 / 94$ & $18 / 43$ \\
\hline Market chaos & $5 / 41$ & $0 / 88$ & $16 / 27$ \\
\hline Technology chaos & $5 / 70$ & $0 / 80$ & $14 / 03$ \\
\hline Product innovation & $1 / 41$ & $0 / 64$ & $28 / 48$ \\
\hline Process innovation & $1 / 27$ & $0 / 88$ & $26 / 73$ \\
\hline Administrative innovation & $1 / 34$ & $0 / 88$ & $28 / 81$ \\
\hline Knowledge creation & $5 / 28$ & $0 / 95$ & $17 / 99$ \\
\hline Knowledge distribution & $5 / 10$ & $0 / 94$ & $18 / 43$ \\
\hline Knowledge application & $5 / 33$ & $0 / 84$ & $15 / 76$ \\
\hline Knowledge maintenance & $5 / 33$ & $1 / 02$ & $19 / 14$ \\
\hline
\end{tabular}

According to KMO test result which is equal to $94 / 0$, the study data are reducible to a number of underlying fundamental factors. The significance level of 0.000 Bartlett's test is significant at the error level of 0/01; this indicates that among the items, the matrix is not the same, and on the one hand there is a high correlation between items within each factor. On the other hand, there is no correlation between items of one factor with items of another factor.

\subsection{The first confirmatory factor analysis of strategic thinking variable}

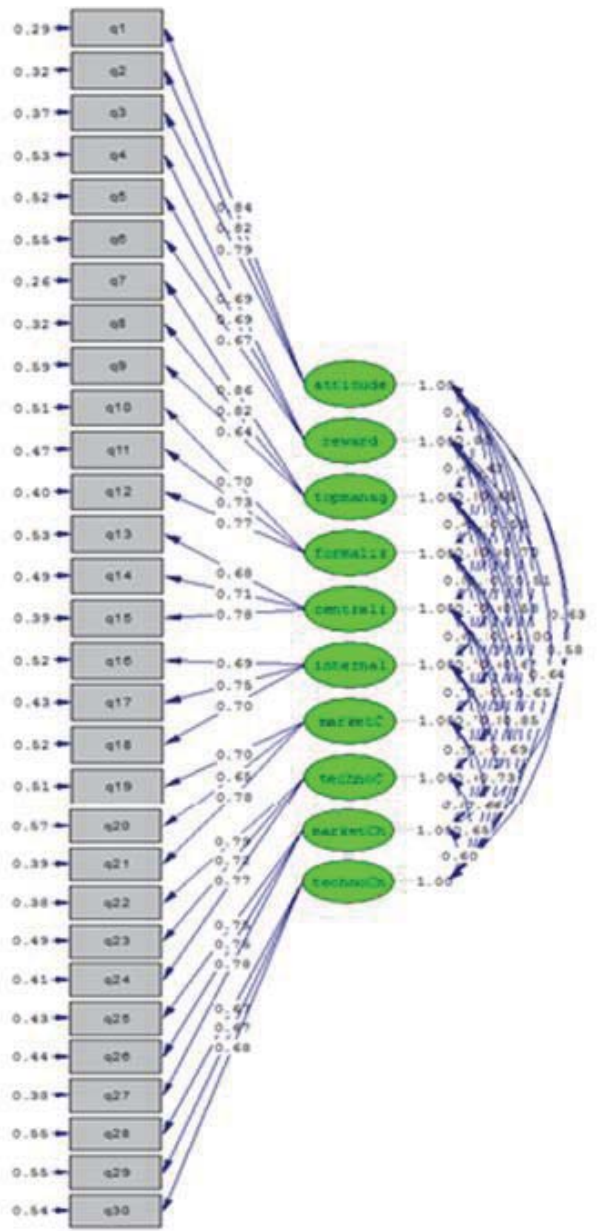

Diagram 1: The first confirmatory factor analysis of strategic thinking with standardized coefficients 
The confirmatory factor analysis of strategic thinking is presented in diagram 10. Standard loadings of confirmatory factor analysis are obtained in order to assess the strength of the relationship between each factor (latent variables) with its observable variables (significant variable) in all aspects of higher than 3.0. According to Table 6, the fit indices are also placed in the proper range; therefore, it can be stated that the model has a good fit.

Table 6: Goodness-of-fit indices of the strategic thinking model

\begin{tabular}{|l|c|c|c|c|c|c|c|c|}
\hline Fit index & CMIN/DF & SRMR & RMSEA & GFI & AGFI & NFI & NNFI & IFI \\
\hline Acceptable values & $<3$ & $<0.05$ & $<0.08$ & $>0.9$ & $>0.9$ & $>0.9$ & $>0.9$ & $>0.9$ \\
\hline Calculated values & 2.07 & 0.048 & 0.060 & 0.86 & 0.82 & 0.96 & 0.98 & 0.98 \\
\hline
\end{tabular}

Table 7: Fit indices

\begin{tabular}{|c|l|c|}
\hline Symbol & Full name of fit index & Acceptable values \\
\hline RMSEA & Root Mean Square Error of Approximation(RMSEA) & $<0.08$ \\
\hline CMIN/DF & - & 3 \\
\hline GFI & Goodness of fit & $>=0.90$ \\
\hline AGFI & Adjusted Goodness of Fit & $>=0.90$ \\
\hline SRMR & Standardized Root Mean Square Residual & $<0.05$ \\
\hline NFI & Normed Fit Index & $>=0.90$ \\
\hline NNFI & Non- Normed Fit Index & $>=0.90$ \\
\hline IFI & Incremental Fit Index & $>=0.90$ \\
\hline
\end{tabular}

Root Mean Square Error of Approximation (RMSEA): This index is based on non-central parameter and is less affected by sample size. This index can measure the mean of fit lack for each degree of freedom. In this model, the amount of it is equal to 0/06; thus, the model has a good fit.

Goodness of Fit (GFI) and Adjusted Goodness of Fit (AGFI): These values are influenced by sample size and for the models that have been determined to be weak can be great. The values greater than 9.0 for these two indices indicate a very good fit of model on the data. In this study, GFI was equal to 0/86 and AGEI was equal to 0/82; this indicates that the data of this study did not fit the model. But considering the suitability of other comparative fit indices (NFI, NNFI and IFI), it can be stated that the fit of model is suitable.

Standardized Root Mean Square Residual (SRMR): Values less than 0/5 show the fit of a good model. In this study, SRMR was equal to 0/04.

Normed Fit Index (NFI), Non- Normed Fit Index (NNFI), and Incremental Fit Index(CFI): Values greater than 0/9 indicate the goodness of fit model for this indices. NFI for this model was 0/96, NNFI was 0/98, and IFI was 0/98. Thus, indices are more than $0 / 9$, and data can fit the model well.

\subsection{The second confirmatory factor analysis of strategic thinking variable}

According to the results of the first confirmatory factor analysis, correlation analysis of all the items simultaneously was confirmed with the strategic thinking model. The relationship between each of the variables of the strategic thinking variable in a second-order factor analysis was as follows: 


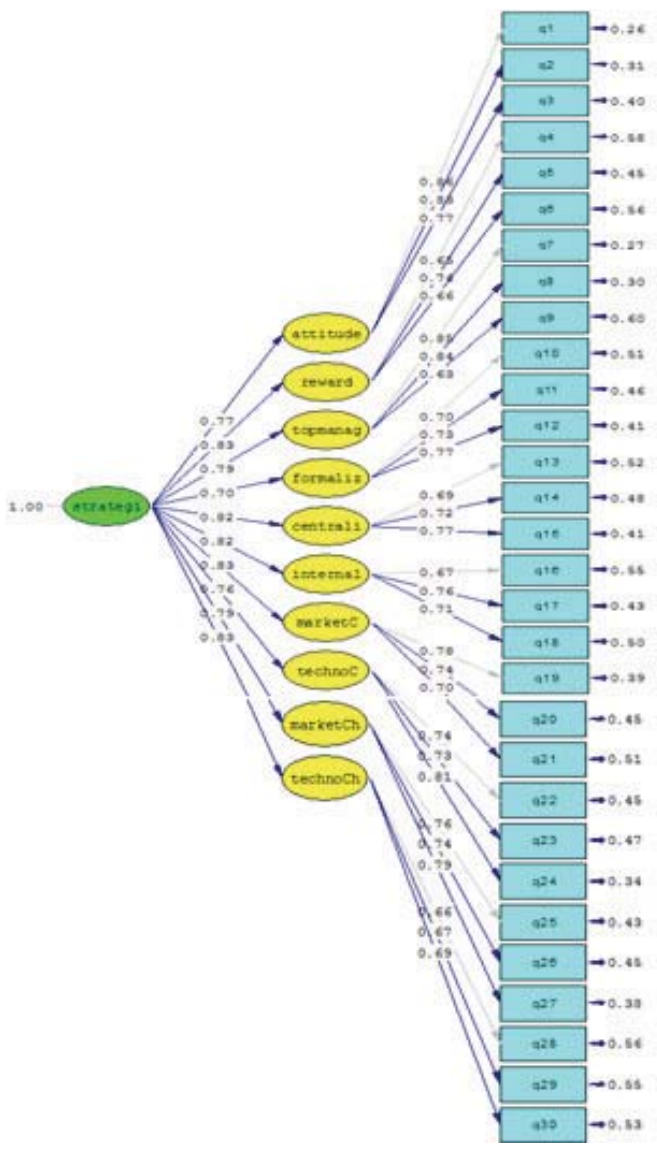

Diagram 2: The second confirmatory factor analysis of strategic thinking with standardized coefficients

The second measurement model seeks to explore first-order latent in the final latent. Because fit indices, that is RMSEA, is $0 / 07$ and smaller than $0 / 08$, and the degree of freedom of the chi-square is equal to $2 / 89$, as well as fit indices of NFI = $.94, \mathrm{NNFI}=.96, \mathrm{IFI}=.96$ are higher than 90 , the model has a suitable fit.

Table 8: The second confirmatory factor analysis of strategic thinking

\begin{tabular}{|l|l|c|c|c|c|}
\hline Dimensions & $\begin{array}{l}\text { Dimensions' } \\
\text { codes }\end{array}$ & Symbol & $\begin{array}{c}\text { Standard } \\
\text { coefficient }\end{array}$ & $\begin{array}{c}\text { Significant } \\
\text { value }\end{array}$ & $\begin{array}{c}\text { The relationship } \\
\text { approval or rejection }\end{array}$ \\
\hline Attitude toward risk & Attitude & $\mathrm{X} 1$ & $0 / 77$ & $12 / 82$ & Approved \\
\hline Award system & Reward & $\mathrm{X} 2$ & $0 / 83$ & $10 / 04$ & Approved \\
\hline Emphases of top managers & Top manager & $\mathrm{X} 3$ & $0 / 79$ & $12 / 91$ & Approved \\
\hline Formalization & Formalization & $\mathrm{X} 4$ & $0 / 70$ & $9 / 43$ & Approved \\
\hline Centralization & Centralization & $\mathrm{X} 5$ & $0 / 82$ & $10 / 73$ & Approved \\
\hline Internal team & Internalteam & $\mathrm{X} 6$ & $0 / 82$ & $10 / 36$ & Approved \\
\hline Market capacity & marketC & $\mathrm{X} 7$ & $0 / 83$ & $10 / 32$ & Approved \\
\hline Technology capacity & TechnoC & $\mathrm{X} 8$ & $0 / 76$ & $10 / 78$ & Approved \\
\hline Market chaos & MarketChaos & $\mathrm{X} 9$ & $0 / 79$ & $11 / 40$ & Approved \\
\hline Technology chaos & technoChaos & $\mathrm{X} 10$ & $0 / 83$ & $10 / 18$ & Approved \\
\hline
\end{tabular}

As can be seen in the above table, the relationship between all variables with strategic thinking can be confirmed (the 
significant value is higher than 1/69). Market capacity, award system, and technology chaos variables with the standard coefficient of 0/83 were most correlated with strategic thinking, and the formalization variable had the lowest correlation with the strategic thinking. The following is the formula of this relationship:

$\mathrm{ST}=.77 \times 1+.83 \times 2+.79 \times 3+.70 \times 4+.82 \times 5+.82 \times 6+.83 \times 7+.76 \times 8+.79 \times 9+.83 \times 10$

\subsection{Test hypotheses using structural equation modeling}

Structural model of research in standardized coefficients and significant value

Table 9: Fit indices

\begin{tabular}{|l|c|c|c|c|c|c|c|c|}
\hline Fit index & CMIN/DF & SRMR & RMSEA & GFI & AGFI & NFI & NNFI & IFI \\
\hline Acceptable values & $<3$ & $<0.05$ & $<0.08$ & $>0.9$ & $>0.9$ & $>0.9$ & $>0.9$ & $>0.9$ \\
\hline Calculated values & 2.23 & 0.042 & 0.064 & 0.94 & 0.90 & 0.97 & 0.98 & 0.99 \\
\hline
\end{tabular}

As table 9 shows, the model had suitable fit indices, because the proportion of chi-square to degree of freedom is equal to 2/23 and smaller than the allowed amount of 3, and the RMSEA is smaller than 0/08. The other fit indices are shown in table 9 which are suitable. Generally, it can be stated that the structural model has a suitable fit.

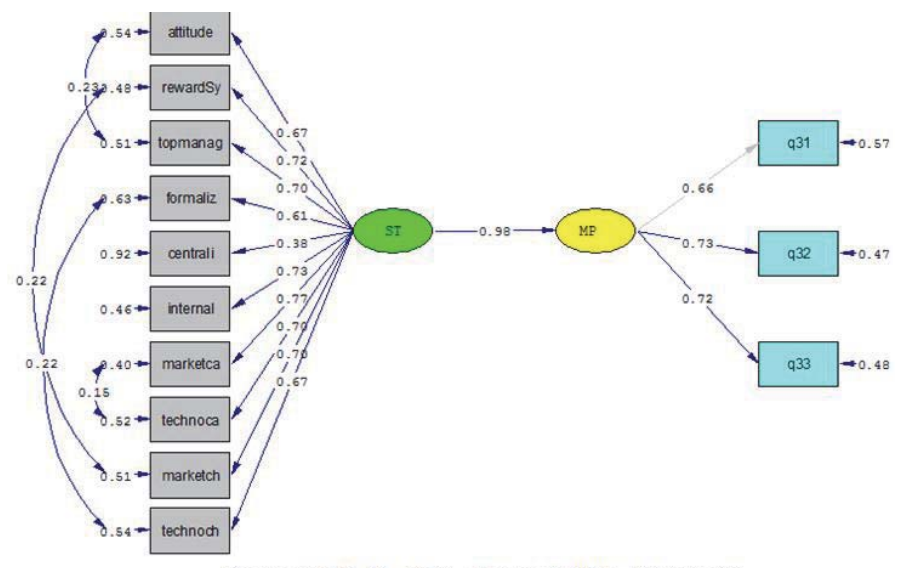

Diagram 3: Structural model of research at standard coefficient mode

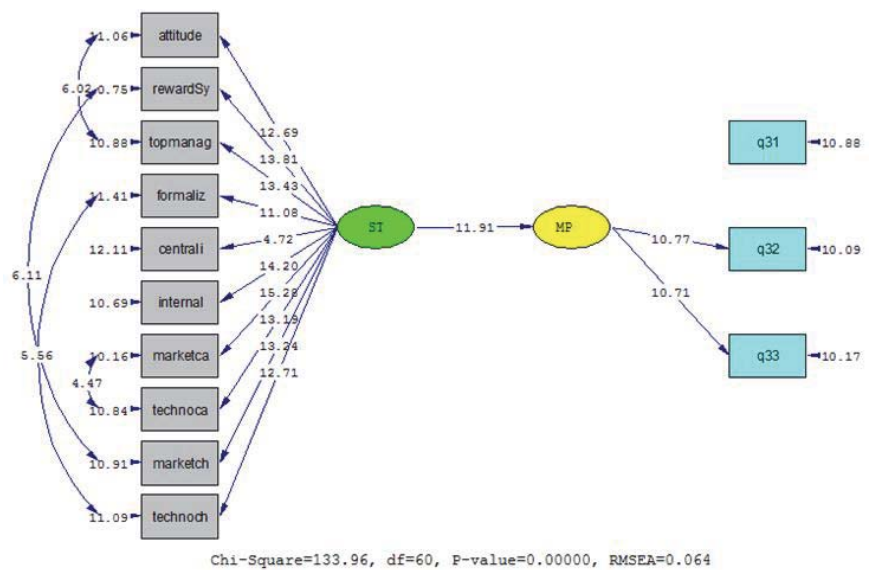

Diagram 4: Structural model of research at significant value mode 
As char 3 and 4 indicate, the relationship between strategic thinking and organizational innovation is very powerful because significant value is $11 / 91$ and higher than $1 / 96$.

\subsection{Structural models to test secondary hypotheses of research}

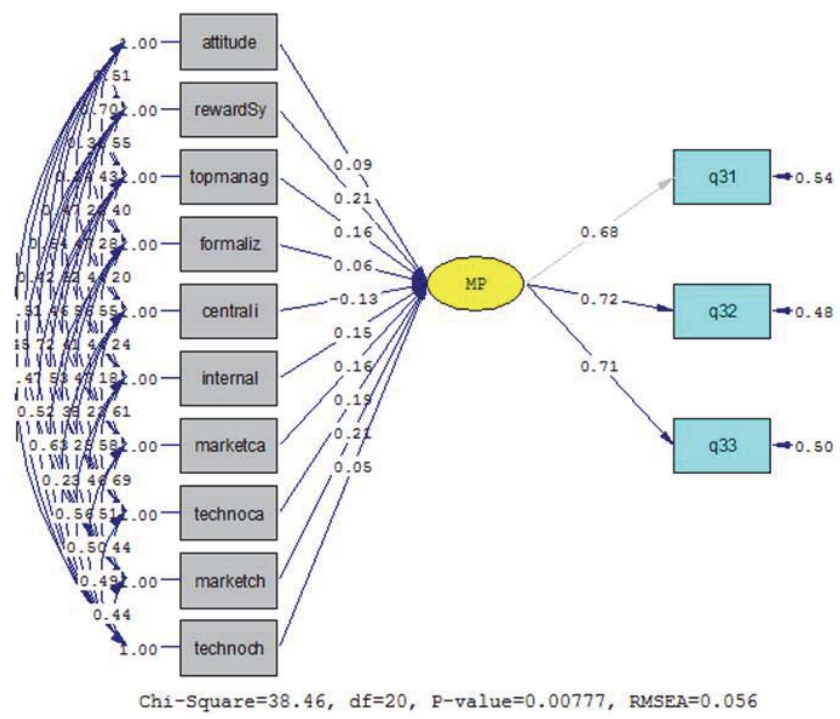

Diagram 5: Structural model of research to test secondary hypotheses in standard coefficient mode

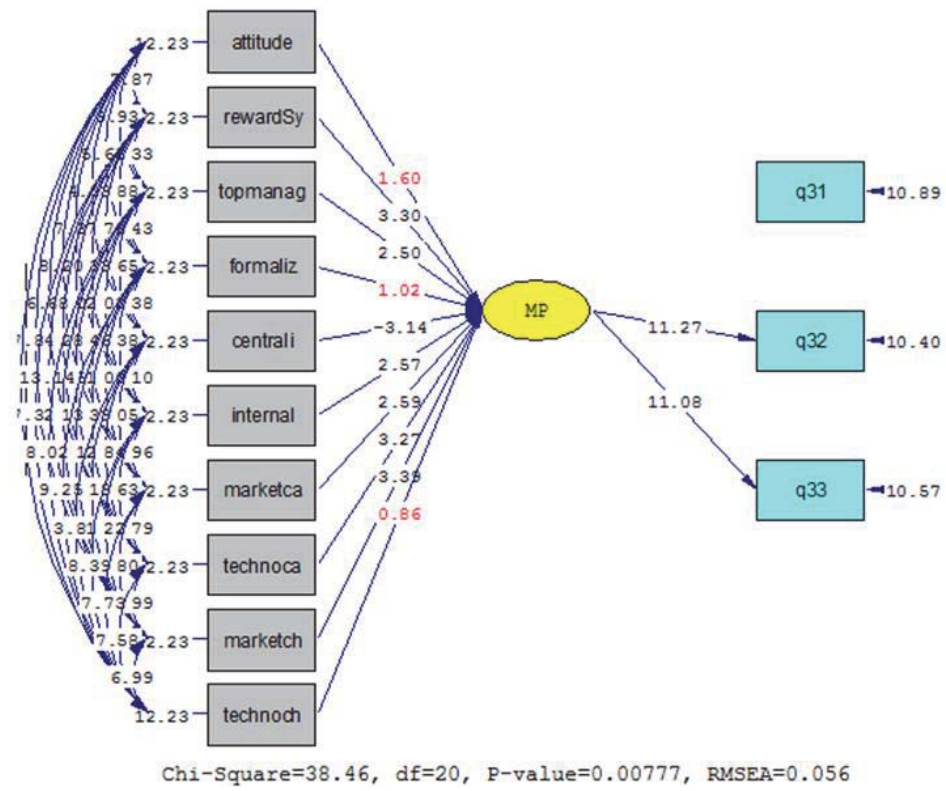

Diagram 6: Structural model of research to test secondary hypotheses in significant value mode 
Table 10: The results of hypothesis testing

\begin{tabular}{|l|l|c|c|c|}
\hline Hypothesis & Coding in diagram & Standard coefficient & Significant value & Test result \\
\hline Strategic thinking-organizational innovation & ST- MP & $0 / 98$ & $11 / 91$ & Approved \\
\hline Attitude toward risk-organizational innovation & Attitude-MP & $0 / 09$ & $1 / 60$ & Rejected \\
\hline Award system-organizational innovation & rewardS-MP & $0 / 21$ & $2 / 30$ & Approved \\
\hline Emphases of top managers-organizational innovation & Topmanager-MP & $0 / 16$ & $2 / 50$ & Approved \\
\hline Formalizaion-organizational innovation & Formalization-MP & $0 / 06$ & $1 / 02$ & Rejected \\
\hline Centralization-organizational innovation & Centralization-MP & $-0 / 13$ & $-3 / 14$ & Approved \\
\hline Internal teams-organizational innovation & Internalteam-MP & $0 / 15$ & $2 / 57$ & Approved \\
\hline Market capacity-organizational innovation & MarketC-MP & $0 / 16$ & $2 / 59$ & Approved \\
\hline Technology capacity-organizational innovation & TechnoC-MP & $0 / 19$ & $3 / 27$ & Approved \\
\hline Market chaos-organizational innovation & MarketingChaos-MP & $0 / 21$ & $3 / 39$ & Approved \\
\hline Technology chaos-organizational innovation & technoChaos-MP & $0 / 05$ & $0 / 86$ & Rejected \\
\hline
\end{tabular}

Main hypothesis: strategic thinking has a significant relationship with organizational innovation.

Null hypothesis: strategic thinking has not a significant relationship with organizational innovation.

Research hypothesis: strategic thinking has a significant relationship with organizational innovation.

The equation of main hypothesis relationship $=$ direct effect + indirect effect

$\mathrm{MP}=.98 \mathrm{ST}+0$

This means that by changing a single unit in strategic thinking, $98 \%$ of organizational innovation changes.

And the rest is interpreted likewise.

\subsection{The first confirmatory factor analysis of knowledge management variable:}

Diagram 7 shows the significant value of the first confirmatory factor analysis of knowledge management variable. According to the diagram, all the available routes are at significant levels (all the estimated parameters are more than 1/96). Therefore, internal correlation between dimensions is significant, and the correlation between questions and dimensions has reached a significant level.

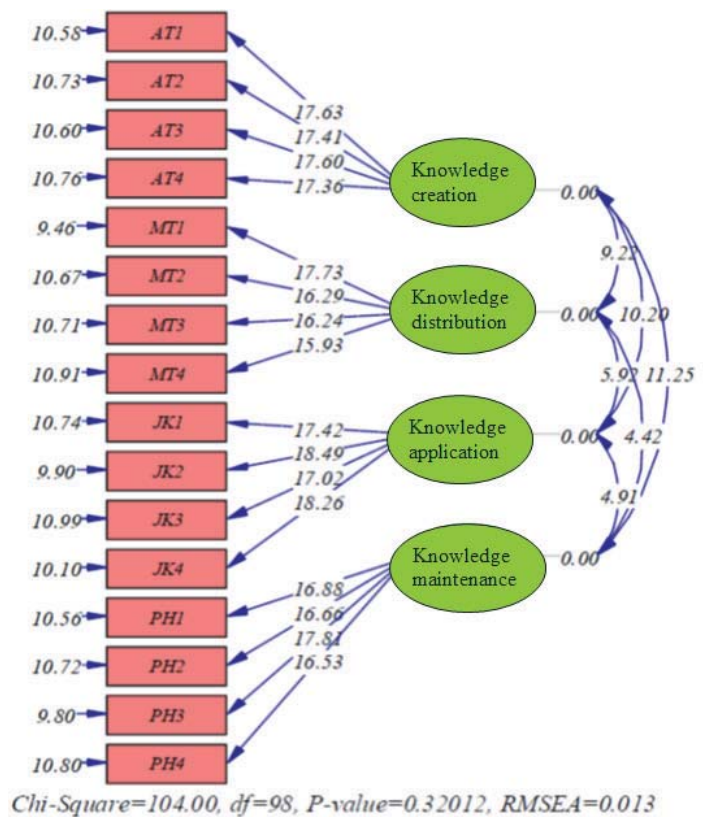

Diagram 7: The significant values of the first confirmatory factor analysis of knowledge management variable 


\subsection{The second confirmatory factor analysis of knowledge management variable:}

Considering the fact that the first confirmatory factor analysis of knowledge management variable confirmed the internal correlations of dimensions and dimensions with questions, in order to investigate whether the relationship between knowledge management variable and its dimensions is significant, the second confirmatory factor analysis was run. Diagram 8 shows the significant values of the second factor analysis. According to this diagram, the estimated parameters for all the routs are significant; thus, the knowledge management structure is reliable. Diagram 9 presents the estimated coefficients of the second-order factor analysis for knowledge management variable in order to prioritize the effects of each dimension on the variable. Table 11 shows the fit indices of the second factor analysis of this variable. According to this table, all the indices are at a favorable level and this structure fits the collected data and is reliable.

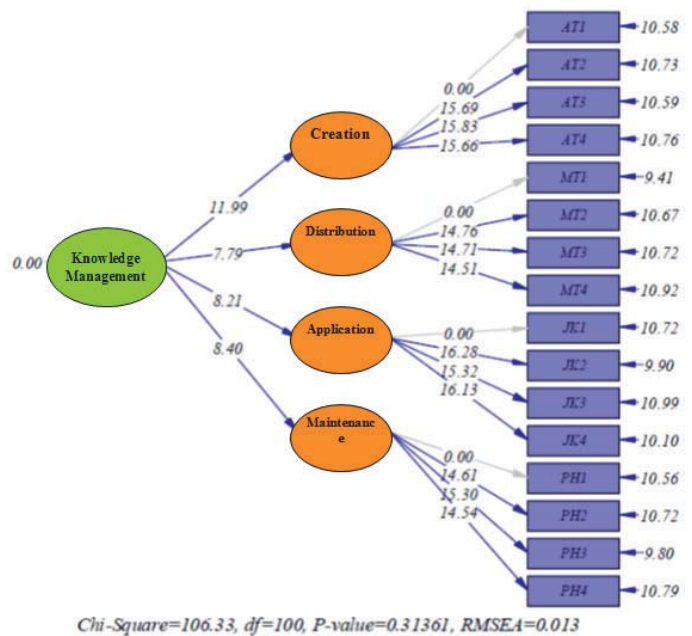

Diagram 8: The significant values of the second confirmatory factor analysis of knowledge management variable

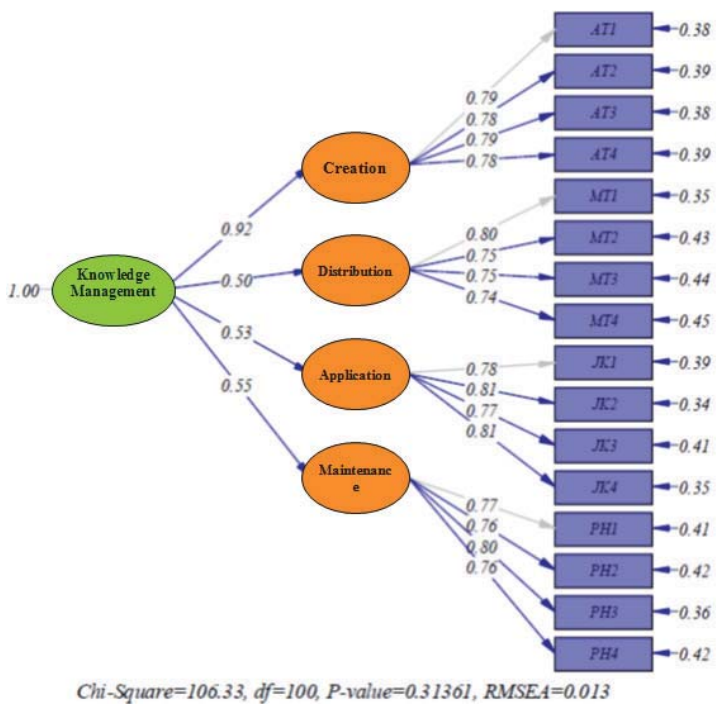

Diagram 9: Coefficients of the standard estimation of the second confirmatory factor analysis of knowledge management variable 
Table 11: Fit indices of the second confirmatory factor analysis of knowledge management variable

\begin{tabular}{|l|c|c|}
\hline Fit index & Suitable amount & Result \\
\hline$X^{2} / d f$ & $<3 / 00$ & $1 / 0633$ \\
\hline GFI(goodness of fit index) & $>0 / 90$ & $0 / 97$ \\
\hline RMSEA(Root Mean Square Error of Approximation) & $<0 / 08$ & $0 / 013$ \\
\hline RMR(root mean square residual) & $<0 / 05$ & $0 / 024$ \\
\hline NFI (Normed Fit Index) & $>0 / 90$ & $0 / 98$ \\
\hline NNFI (Non-Normed Fit Index) & $>0 / 90$ & $1 / 00$ \\
\hline CFI (Comparative Fit Index) & $>0 / 90$ & $1 / 00$ \\
\hline
\end{tabular}

In order to easily interpret the results of the the second confirmatory factor analysis of knowledge management variable, the estimated parameters of these two diagrams are summarized in table 12.

Table 12: The results of the second confirmatory factor analysis of knowledge management variable

\begin{tabular}{|c|c|c|c|c|c|c|}
\hline Variable & Dimensions & $\begin{array}{l}\text { Significant Value } \\
\text { (t-value) }\end{array}$ & $\begin{array}{c}\text { Path } \\
\text { coefficient } \beta\end{array}$ & Rank & $\begin{array}{c}\text { Squared multiple } \\
\text { correlation }\left(\mathrm{R}^{2}\right)\end{array}$ & $\begin{array}{c}\text { Error } \\
\text { variance }\end{array}$ \\
\hline \multirow{4}{*}{ 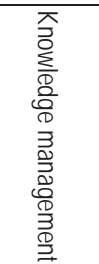 } & $\begin{array}{l}\text { Knowledge } \\
\text { creation }\end{array}$ & $11 / 99$ & $0 / 92$ & 1 & $0 / 84$ & 0/16 \\
\hline & $\begin{array}{l}\text { Knowledge } \\
\text { distribution }\end{array}$ & $7 / 79$ & $0 / 50$ & 4 & $0 / 25$ & $0 / 75$ \\
\hline & $\begin{array}{l}\text { Knowledge } \\
\text { application }\end{array}$ & $8 / 21$ & 0/53 & 3 & 0/28 & 0/72 \\
\hline & $\begin{array}{l}\text { Knowledge } \\
\text { maintenance }\end{array}$ & $8 / 40$ & 0/55 & 2 & 0/31 & $0 / 69$ \\
\hline
\end{tabular}

Table 12 shows the interpretation of the results of the estimation of the second confirmatory factor analysis of knowledge management variable. For instance, one of the dimensions is explained below:

The significant level between knowledge management and knowledge creation dimension is 11/99 which is larger than $1 / 96$. This indicates that the relationship between knowledge management variable and knowledge creation dimension is significant at $99 \%$ level. The multiple correlations square of this path is $0 / 84$ which indicates that knowledge creation dimension (84\%) explains the changes of knowledge management variable. In addition, the coefficient path between these two variables is 0/92 which shows the effectiveness of knowledge creation dimension as an effective factor on knowledge management. Knowledge creation dimension is the most effective factor on knowledge management in comparison with other coefficients.

Composite reliability of the knowledge management structure was 0/73 using the following formula. Because the composite reliability is higher than $0 / 6$, knowledge management structure has an acceptable reliability.

$$
P_{c}=(0 / 92+0 / 50+0 / 53+0 / 55)^{2} \div\left[(0 / 92+0 / 50+0 / 53+0 / 55)^{2}+(0 / 16+0 / 75+0 / 72+69)\right]=0 / 73
$$

\section{Discussion and Conclusion}

According to the results of the main and subsidiary hypotheses, it can be concluded that all the dimensions and components (such as attitude of the top managers toward risk taking, award systems, emphases of top managers, formalization in organizational structure, centralization in organizational structure, internal organizational teams, marketing capacity, technology capacity, market chaos, technology chaos) had correlation with knowledge management and organizational innovation.

The findings showed that formalization in organization, award systems, emphases of top managers, attitudes of top managers toward risk taking had correlation with knowledge management as well as organizational innovation. In addition, centralization in organizational structure, marketing capacity, and internal teams had correlation with knowledge management and organizational innovation; these results are in line with the findings of Moon et al. (2013). (9)

The results indicated that marketing and technology capacity had correlation with knowledge management and organizational innovation. Moreover, marketing and technology chaos had correlation with knowledge management and organizational innovation. These findings are consistent with the findings of Moon et al. (2013). (9) 


\section{Suggestions}

1. According to the results of the study, it is suggested that in developing organizational procedures, attitudes and perpectives of top managers regarding konowledge management, organizational innovation, and risk taking should be taken into account.

2. It is suggested that top managers should pay attention to creativity in organization and make sure that creativity becomes a part of the organization's personality and becomes its cornerstone. Harnessing the energies and talents of people requires understanding of the factors that foster innovation and creativity.

3. It is suggested that managers should be accountable and avoid baming. They should collaborate to fix the employees' problems and seek solution. Moreover, they should unite different individuals with different thoughts.

4. Managers should follow unity, synergy, and centralization in the form of strategic thinking management.

5. It is also suggested that managers focus on strategic thinking with various working groups of the organizarion based on cooperation between individuals within the organization which will have strategic importance for the organization within 5 or 10 years.

6. According to the results, it is also suggested that managers should highlight strategic thinking in both individual and organizational level so that senior managers become capable of drawing a wider range of possible strategies to improve strategic thinking in their organizations.

7. It is suggested that the capacity of the strategy-driven technologies should be reflected in knowledge management and organizational innovation.

8. Finally, it is suggested that managers should design a warning system; that is, a scenario, a rapid response system for the management and marketing during the economic crisis and other chaotic conditions must be designed.

\section{Reference}

1-Abraham, S. (2005). Stretching strategic thinking. Strategy \& Leadership, 33(5).

2-Adner, R., \& Kapoor, R. (2010). Value creation in innovation ecosystems: How the structure of technological interdependence affects firm performance in new technology generations. Strategic Management Journal, 31(3).

3-Akgun, A. E., Lynn, G. S., \& Yilmaz, C. (2006). Learning process in new product development teams and effects on product success: A socio-cognitive perspective. Industrial Marketing Management, 35(2)

4-Ann Langley, (2002),"The Roles of formal Strategic Planning" Long Range Planning, no3.

5-Enright, M. (2004); The Globalization of competition and the localization of Competitive Advantage: Policies toward Regional Clustering in Hood, N. and Young S. (Eds) Globalization of Multinational Enterprise and Economic development, Macmillan, London.

6-Fairholm, M., \& Card, M. (2013). Perspectives of strategic thinking: From controlling chaos to embracing it. Journal of Management and Organization, 15(1)

7-Fodness, D. (2014). rethinking strategic marketing: Achieving breakthrough results. Journal of Business Strategy, 26(3).

8-Mehmet Haluk Ko"ksal (2008), how export marketing research affects company export, Marketing Intelligence \& Planning, Vol. 26 No. 4

9-Moon, B. J. (2006). Determinants and outcomes of radical product innovations by Korean firms. Journal of Global Academy of Marketing Science, 16(4)

10-Moon, Byeong-joon .Antecedents and outcomes of strategic thinking ,Journal of Business Research., 2013, vol. 66, issue 10, pages 1698-1708

11- Alinejad V, Shadmehr A, kazemi Asfeh Sh, Gholizade R, Tabbakhi E. Examine the Relationship Between Organizational Citizenship Behavior and Organizational Health in Specialty and Subspecialty Seyyed-al-Shohada Hospital Staff, Urmia. The Social Sciences. 2016, Volume: 11 , Issue: 6, Page No.: 910-917 DOI: 10.3923/sscience.2016.910.917.

12- Alinejad V, Shadmehr A, Investigation of the Factors Affecting the Positivity of the Transplant Result. The Social Sciences. 2016 , Volume: 11 , Issue: 6, Page No.: 906-909 DOI: 10.3923/sscience.2016.906.909

13- Farrokh-Eslamlou H, Oshnouei S, Alinejad V. Novel restricted access to vasectomy in Iran: addressing changing trends in vasectomy clients' characteristics over 16 years in northwestern Iran. Contraception. 2015 Nov;92(5):488-93. doi: 10.1016/j.contraception. 2015.07.010. Epub 2015 Jul 28.

14- Hosseinlou A, Alinejad V, Alinejad M, Aghakhani N. The effects of fish oil capsules and vitamin B1 tablets on duration and severity of dysmenorrhea in students of high school in Urmia-Iran. Glob J Health Sci. 2014 Sep 18;6(7 Spec No):124-9.doi: 10.5539/gjhs.v6n7p124.

15- Khademvatan K, Alinejad V, Eghtedar S, Rahbar N, Agakhani N. Survey of the relationship between metabolic syndrome and myocardial infarction in hospitals of Urmia University of medical sciences. Glob J Health Sci. 2014 Sep 18;6(7 Spec No):58-65. 
doi: 10.5539/gjhs.v6n7p58.

16- Alinejad V, Mahmodi M, Alinejad M, Besharat E, Gholizade R, Tabbakhi E, Shojaei Pour A, Gharaaghaji R. Investigation of long- and short-term relationships between cesarean delivery and its effective factors in Malayer. Glob J Health Sci. 2014 Sep 18;6(7 Spec No):1-7. doi: 10.5539/gjhs.v6n7p1.

17- Niknejad E, Alinejad V ,Samarei R, The Review of Factors Affecting the Hospitalization Period of Patients with Fractures under the Age of 10. Research Journal of Medical Sciences2016, Volume: 10 , Issue: 2 , Page No.: 32-35. DOI: 10.3923/rjmsci.2016.32.35

18- Niknejad E, Alinejad, Factors Affecting the Duration of Decay of the First Permanent Molar Tooth. Research Journal of Medical Sciences2016, Volume: 10 , Issue: 2 , Page No.: 36-38 DOI: 10.3923/rjmsci.2016.36.38

19-Rahimi-Rad MH, Eishi A. Superior vena cava syndrome in a man with situs inversus totalis and left main bronchus cancer. Pneumologia. 2009 Jan-Mar;58(1):52-4.

20-Eishi A, Rahimi E, Akhavan S, Shahgaibi S, Fariba F. Cancer during pregnancy: a review of 10 years of experience. Pak J Biol Sci. 2012 Apr 1;15(7):341-6.

21-Rahimi-Rad MH, Asgari B, Hosseinzadeh N, Eishi A. Eosinopenia as a Marker of Outcome in Acute Exacerbations of Chronic Obstructive Pulmonary Disease. Maedica (Buchar). 2015 Mar;10(1):10-3. 